\title{
Association of miR-21, miR-126 and miR-605 gene polymorphisms with ischemic stroke risk
}

\author{
Yang Xiang ${ }^{1}$, Jing Guo ${ }^{2}$, You-Fan Peng ${ }^{1}$, Tan Tan ${ }^{1}$, Hua-Tuo Huang ${ }^{1}$, Hong-Cheng \\ Luo $^{1}$ and Ye-Sheng Wei ${ }^{1}$ \\ ${ }^{1}$ Department of Clinical Laboratory, The Affiliated Hospital of Youjiang Medical University for Nationalities, Baise 533000, \\ Guangxi, China \\ ${ }^{2}$ Department of Dermatology, The Affiliated Hospital of Youjiang Medical University for Nationalities, Baise 533000, Guangxi, \\ China \\ Correspondence to: Ye-Sheng Wei, email: wysh1186@163.com \\ Keywords: ischemic stroke; microRNAs; gene; single nucleotide polymorphisms; association analysis \\ Received: May 23, $2017 \quad$ Accepted: August 23, $2017 \quad$ Published: September 28, 2017 \\ Copyright: Xiang et al. This is an open-access article distributed under the terms of the Creative Commons Attribution License 3.0 \\ (CC BY 3.0), which permits unrestricted use, distribution, and reproduction in any medium, provided the original author and source \\ are credited.
}

\section{ABSTRACT}

We investigated whether three common microRNA polymorphisms (miR-21T>C [rs1292037], miR-126G>A [rs4636297] and miR-605T>C [rs2043556]) were associated with ischemic stroke (IS) risk in a Chinese population. The study population comprised 592 ischemic stroke patients and 456 normal controls. The polymorphisms were measured using Snapshot SNP genotyping assays and confirmed by sequencing. Relative expressions of miR-21, miR-126 and miR-605 were measured by quantitative real-time PCR. We found that miR-126 gene rs4636297 polymorphism was associated with decreased ischemic stroke risk (GA vs. GG: $A O R=0.64$, adjust $P=0.025$; $A$ A vs. GG: $A O R=0.32$, adjust $P=0.007$; dominant model: $A O R=0.58$, adjust $P=0.004$ ). $M i R-21$ gene rs1292037 and miR-605 gene rs2043556 polymorphisms were not associated with ischemic stroke risk. In addition, compared with normal controls, serum miR-126 level was significantly decreased in ischemic stroke patients, while the miR-21 level was significantly increased. Importantly, patients carrying rs4636297 GA/AA genotypes had higher serum miR-126 level $(P<0.05)$. MiR-126 gene rs4636297 polymorphism and serum miR-126/-21 levels are associated with ischemic stroke risk. Our data indicates that miR-126 and miR-21 play roles in the development of ischemic stroke.

\section{INTRODUCTION}

Ischemic stroke is a common cerebral blood circulation disorder disease which is a serious threat to human health. It is the second leading cause of death in China [1]. Its growing trend of prevalence deserves the attention of medical community worldwide. Common risk factors, such as age, gender, smoking, hypertension and abnormal lipid metabolism account for part of the prevalence of ischemic stroke [2-5]. Genetic factors have been defined as important risk contributors to the pathogenesis of ischemic stroke [6-8].

MicroRNAs (miRNAs) are class of small noncoding single-stranded RNAs molecules of about 21-23 nucleotides in length, which involve in regulating gene expressions and contribute to various disease pathogenesis, such as inflammation, cancer, atherosclerosis, and ischemic stroke [9-13]. Atherosclerosis start from the dysfunction endothelial cells (ECs) which was regard to be a major cause of ischemic stroke. ECs enriched microRNAs, such as miR-21 and miR-126 have been found to be involved in the progression of atherosclerosis by modulating the function of ECs $[14,15]$. For instance, miR-21 involved in the regulation of angiogenesis mediated by ECs [16]; microRNA-126-5p promotes endothelial proliferation and limits atherosclerosis by suppressing DIk1 [17]. In addition, the serum level of miR-21 and miR-126 were significantly changed in 
ischemic stroke and atherosclerosis patients [18-20]. The exact mechanism of the abnormal miR-21 and miR-126 expression remain unclear and genetic factors may play key roles in this process [21].

Single nucleotide polymorphisms in microRNAs were related to individual's susceptibility to a number of human diseases [22-24]. Polymorphisms in microRNAs were reported to be associated with ischemic stroke risk [25-27]. Recently, three common microRNA polymorphisms (miR-126G >A: rs4636297, chromosome 9, 139565150; miR-21T>C: rs1292037, chromosome 17, 57918908; miR-605T $>$ C: rs2043556, chromosome 10, 53059406) have been investigated in a variety of human diseases [28-34]. Up to now, no report was performed to examine the association between these three common SNPs (i.e. rs4636297, rs2043556 and rs1292037) and ischemic stroke risk. Based on this background, we hypothesized that these three polymorphisms may relate to ischemic stroke risk. Therefore, we performed the study in a Chinese population, for the first time, to evaluate the association between $\mathrm{rs} 4636297 \mathrm{G}>\mathrm{A}, \quad \mathrm{rs} 2043556 \mathrm{~T}>\mathrm{C}$ and rs1292037T $>$ C polymorphisms and ischemic stroke susceptibility and to assess the associations between these three polymorphisms and the expression levels of miR21/-126/-605.

\section{RESULTS}

\section{Clinical characteristics of the study participants}

The clinical characteristics of the study subjects were shown in Table 1. There is no significant difference between cases and controls with regard to age $(\mathrm{P}=0.884)$, gender $(\mathrm{P}=0.609)$ and HDL-C levels $(\mathrm{P}=0.200)$. Ischemic stroke patients were significantly more likely to smoke and have higher percentage of diabetes mellitus, hypertension, as well as high serum TC, TG and LDL-C levels (both $\mathrm{P}<0.05)$.

\section{Genotype distributions of the three microRNAs polymorphisms in patients and controls}

All of the polymorphisms have three genotypes respectively. The genotype and allele frequencies of rs4636297, rs1292037 and rs2043556 polymorphisms in case and control groups were shown in Table 2 . The genotype distributions of the three polymorphisms in both cases and controls were in HWE (both $\mathrm{P}>0.05$ ). The power of rs4636297polymorphism was 0.99. We calculated the adjusted odds ratio (AOR) from logistic regression analyses with respect to age, gender, hypertension, diabetes mellitus, smoking, TC, TG, LDL-C and HDL-C. Compared with rs4636297 GG genotype, rs4636297 GA and AA genotypes were significantly associated with decreased risk of ischemic stroke (GA vs. GG: $A O R=0.64$, 95\% CI, 0.44-0.95, $\mathrm{P}=0.025$; AA vs. GG: $\mathrm{AOR}=0.32,95 \%$
CI, 0.14-0.74, $\mathrm{P}=0.007$; dominant model, $\mathrm{AA}+\mathrm{GA}$ vs. GG: $\mathrm{AOR}=0.58,95 \% \mathrm{CI}, 0.40-0.84, \mathrm{P}=0.004)$. However, rs1292037 and rs2043556 polymorphisms were not significantly associated with ischemic stroke risk.

\section{Stratified analyses}

Stratified analyses based on age, gender, hypertension, smoke, diabetes mellitus, and hyperlipidemia were performed to find additional clinical significance. According to the results, we failed to find any association between these three polymorphisms and clinical characteristics of ischemic stroke. (Table 3)

\section{Relative expressions of miR-21, miR-126 and miR-605}

Relative serum miR-21, miR-126 and miR-605 levels were detected in both ischemic stroke patients and control subjects. Serum levels of miR-126 were significantly decreased in stroke patients compared with normal controls (IS vs. control $=6.57 \pm 1.50$ vs. $9.86 \pm 1.92$, $\mathrm{P}<0.001$; Figure 1A). Patients carrying rs4636297GA/ AA genotypes had significant higher serum levels of miR-126 (GG vs. GA/AA=6.08 \pm 1.47 vs. $7.53 \pm 2.00$, $\mathrm{P}<0.001$; Figure 1B). In normal controls rs $4636297 \mathrm{G}>\mathrm{A}$ polymorphism did not associated with serum miR-126 level (GG vs. $\mathrm{GA} / \mathrm{AA}=9.77 \pm 1.67$ vs. $10.6 \pm 1.19, \mathrm{P}=$ 0.485 ; Figure $1 \mathrm{C}$ ). MiR-21 was significantly increased in ischemic stroke patients (IS vs. control $=34.65 \pm 7.26$ vs. $26.89 \pm 6.81, \mathrm{P}<0.001)$. But, rs 1292037T $>$ C polymorphism did not associated with the expression of miR-21(IS: TT vs. $\mathrm{TC} / \mathrm{CC}=32.5 \pm 5.80$ vs. $35.27 \pm 8.70, \mathrm{P}=0.203$; Control: TT vs. $\mathrm{TC} / \mathrm{CC}=25.64 \pm 6.94$ vs. $27.51 \pm 6.75, \mathrm{P}=0.320$, respectively). Serum miR-605 levels between patients and controls showed no significant difference (IS vs. control $=21.03 \pm 8.53$ vs. $19.21 \pm 9.15, \mathrm{P}=0.262$ ). Besides, serum miR-605 levels did not associated with any genotype of rs2043556 T $>\mathrm{C}$ polymorphism (IS: TT vs. $\mathrm{TC} / \mathrm{CC}=21.26 \pm 9.19$ vs. 20.70 $\pm 7.68, \mathrm{P}=0.802$; Control: TT vs. $\mathrm{TC} / \mathrm{CC}=20.12 \pm 8.65$ vs. $17.93 \pm 9.85, \mathrm{P}=0.363$, respectively).

\section{DISCUSSION}

This is the first study to evaluate the association between three common microRNA polymorphisms (rs4636297G $>$ A, rs1292037T $>C$ and $r$ 2043556T $>C$ ) and ischemic stroke risk in a Chinese population. We demonstrated for the first time that miR-126 gene rs4636297G $>$ A polymorphism was associated with a reduced risk of ischemic stroke. Moreover, patients carrying rs4636297 GA/AA genotypes had a higher level of miR-126. These results indicated that miR-126 gene rs4636297G $>$ A polymorphism may play a role in the progression of ischemic stroke. 
Table 1: Clinical characteristics of the study population

\begin{tabular}{|c|c|c|c|}
\hline Variable & Stroke patients, $n=592(\%)$ & Control subjects, $n=456(\%)$ & $P$ value \\
\hline Age $($ mean $\pm \mathrm{SD})$ & $64.7 \pm 11.5$ & $64.0 \pm 13.5$ & 0.884 \\
\hline Gender $(\mathrm{M} / \mathrm{F})$ & $367 / 225$ & $275 / 181$ & 0.609 \\
\hline Diabetes mellitus & $154(17.6)$ & $55(12.1)$ & 0.015 \\
\hline Hypertension & $304(51.4)$ & $155(34.0)$ & $<0.001$ \\
\hline Smoke & $226(38.2)$ & $142(26.8)$ & $<0.001$ \\
\hline Hyperlipidemia & $290 / 302$ & $128 / 328$ & $<0.001$ \\
\hline $\mathrm{TC}(\mathrm{mmol} / \mathrm{L})$ & $5.13 \pm 0.79$ & $3.87 \pm 0.72$ & $<0.001$ \\
\hline $\mathrm{TG}(\mathrm{mmol} / \mathrm{L})$ & $1.85 \pm 0.89$ & $1.48 \pm 0.52$ & $<0.001$ \\
\hline LDL-C(mmol/L) & $2.63 \pm 0.99$ & $2.16 \pm 0.97$ & $<0.001$ \\
\hline HDL-C(mmol/L) & $1.62 \pm 0.48$ & $1.66 \pm 0.51$ & 0.200 \\
\hline
\end{tabular}

Hyperlipidemia: Hyperlipidemia was defined as a high fasting serum total cholesterol level $(>6.22 \mathrm{mmol} / \mathrm{L})$ or an antihyperlipidemic agent treatment history, TC: total cholesterol, TG: triglyceride, HDL-C: high-density lipoprotein cholesterol, LDL-C: low-density lipoprotein cholesterol.

Atherosclerosis is a hyperlipidemia-induced chronic inflammatory process of the arterial wall, resulting from the disturbed endothelial cells (ECs). It was regard to be a major cause of stroke. The integrity of the endothelial monolayer is fundamental for the homoeostasis of the vascular system, and functional endothelial cells are also required for the growth of new blood vessels during neovascularization [16], endothelial cell functions and angiogenesis are critically regulated by microRNAs, including miR-126, miR-143 and miR-145 et al [35]. The endothelial cell-specific miR-126 is transferred in micro-vesicles from apoptotic endothelial cells and plays important roles in vascular inflammation related diseases, including chronic kidney disease [36, 37], atherosclerosis $[38,39]$ and stroke [10]. In ischemic stroke etiology, miR126 modulates the pathogenic processes of atherosclerosis thereby affecting the stroke progression [40]. These studies indicated that miR-126 may play important role in the development of ischemic stroke. However, the association between $\mathrm{rs} 4636297 \mathrm{G}>\mathrm{A}$ polymorphism in miR-126 gene and ischemic stroke risk remains unclear.

MiR-126 gene is located in chromosome 9q34.3 within the host gene encoding epidermal growth factor-like protein 7 (EGFL7) [41]. Several reports have explored the association between $\mathrm{rs} 4636297 \mathrm{G}>\mathrm{A}$ polymorphism and human disease susceptibility. Results were inconsistent. Rs4636297 G>A polymorphism was not associated with breast cancer and non-small cell lung cancer risk [29, 30]. While, another report indicated that A allele of $\mathrm{rs} 4636297 \mathrm{G}>\mathrm{A}$ can impair the inhibition of mature miR-126 to increase VEGF promotion and increase the risk for developing sight threatening diabetic retinopathy (STDR) [34]. In addition, a functional study revealed that both major $\mathrm{G}$ and minor A allele of rs4636297G $>$ A can blocks the processing of primary miR-126 to precursory miR-126 and resulting in significantly reduced mature miR-126 expression, although the block effect of minor A allele is less effective [21]. In this study, we investigated the association between miR-126 gene rs4636297G $>$ A polymorphism and ischemic stroke risk and the miR-126 expression. According to the results, we found that miR126 gene rs4636297G $>$ A polymorphism was associated with a reduced risk of ischemic stroke and serum level of miR-126 was significantly reduced in stroke patients. Besides, patients carrying GA/AA genotypes had higher miR-126 levels compared with those carrying GG genotypes. With regard to the potential mechanism, we speculated that $\mathrm{rs} 4636297 \mathrm{G}>\mathrm{A}$ polymorphism may exert influence on the processing of primary miR-126 to precursory miR-126 in ischemic stroke patients. Owing to the relative low inhibiting functions of $\mathrm{A}$ allele, patients carrying GA/AA genotypes had a higher level of miR-126 compared with those carrying GG genotype. However, we should not ignore the fact that in normal controls the miR-126 levels did not associated with any rs4636297G $>$ A genotypes. The reason of this difference remains unclear; a possible explanation may be that the miR-126 expression is inducible and its expression is changed after stimulation. The miR-126 levels may be determined by both genetic and inducing factors. Further gene-environment interaction analysis may better reveal the role of miR-126 gene polymorphisms in the etiology of ischemic stroke.

Vascular smooth muscle cell (VSMC)-enriched miR21 was involved in the pathogenesis of atherosclerosis related disease [42]. Consistent with previous studies, we also detected significantly increased serum miR-21 levels in ischemic stroke patients. However, the current 
Table 2: Genotype frequencies of microRNAs polymorphisms between ischemic stroke patients and control subjects

\begin{tabular}{|c|c|c|c|c|c|c|}
\hline Polymorphisms & Stroke, $n=592$ & Control, $n=456$ & OR(95\% CI) & $\mathbf{P}$ & $\operatorname{AOR}^{*}(95 \% \mathrm{CI})$ & $\mathbf{P}^{*}$ \\
\hline \multicolumn{7}{|l|}{ miR-126 rs4636297G/A } \\
\hline GG & $430(72.6)$ & $275(60.3)$ & 1.000 (reference) & & 1.000(reference) & \\
\hline GA & $147(24.8)$ & $154(33.8)$ & $0.61(0.47-0.80)$ & $<0.001$ & $0.64(0.44-0.95)$ & 0.025 \\
\hline AA & $15(2.5)$ & $27(5.9)$ & $0.36(0.19-0.68)$ & 0.001 & $0.32(0.14-0.74)$ & 0.007 \\
\hline $\begin{array}{l}\text { Dominant model }(\mathrm{AA}+\mathrm{GA} \\
\text { vs. GG) }\end{array}$ & & $0.57(0.44-0.74)$ & $<0.001$ & $0.58(0.40-0.84)$ & 0.004 & \\
\hline $\begin{array}{l}\text { Recessive model(AA vs. } \\
\text { GA+GG) }\end{array}$ & & $0.41(0.22-0.79)$ & 0.006 & $0.37(0.16-0.82)$ & 0.015 & \\
\hline Allele A frequency & $177(14.9)$ & $208(22.8)$ & & & & \\
\hline \multicolumn{7}{|l|}{ miR-21 rs1292037T/C } \\
\hline TT & $172(29.1)$ & $152(33.3)$ & 1.000(reference) & & 1.000(reference) & \\
\hline $\mathrm{CT}$ & $304(51.4)$ & $229(50.2)$ & $1.12(0.89-1.55)$ & 0.259 & $1.21(0.81-1.80)$ & 0.349 \\
\hline $\mathrm{CC}$ & $116(19.6)$ & $75(16.4)$ & $1.37(0.95-1.97)$ & 0.091 & $1.47(0.86-2.50)$ & 0.159 \\
\hline $\begin{array}{l}\text { Dominant model }(\mathrm{CC}+\mathrm{CT} \\
\text { vs. TT })\end{array}$ & & & $1.22(0.94-1.59)$ & 0.137 & $1.28(0.88-1.86)$ & 0.204 \\
\hline $\begin{array}{l}\text { Recessive model(CC vs. } \\
\mathrm{CT}+\mathrm{TT})\end{array}$ & & & $1.24(0.90-1.71)$ & 0.191 & $1.37(0.85-2.21)$ & 0.192 \\
\hline Allele $\mathrm{C}$ frequency & $536(45.3)$ & $379(41.6)$ & & & & \\
\hline \multicolumn{7}{|l|}{ miR-605 rs2043556 T/C } \\
\hline TT & $332(56.1)$ & $276(60.5)$ & 1.000 (reference) & & 1.000 (reference) & \\
\hline $\mathrm{CT}$ & $232(39.2)$ & $153(33.6)$ & $1.26(0.97-1.63)$ & 0.080 & $1.41(0.98-2.04)$ & 0.093 \\
\hline $\mathrm{CC}$ & $28(4.7)$ & $27(5.9)$ & $0.86(0.50-1.50)$ & 0.598 & $0.65(0.29-1.50)$ & 0.316 \\
\hline $\begin{array}{l}\text { Dominant model }(\mathrm{CC}+\mathrm{CT} \\
\text { vs. TT })\end{array}$ & & & $1.20(0.94-1.54)$ & 0.148 & $1.31(0.92-1.86)$ & 0.140 \\
\hline $\begin{array}{l}\text { Recessive model(CC vs. } \\
\mathrm{CT}+\mathrm{TT})\end{array}$ & & & $0.79(0.46-1.36)$ & 0.385 & $0.60(0.27-1.34)$ & 0.212 \\
\hline Allele $\mathrm{C}$ frequency & $288(24.3)$ & $207(22.7)$ & & & & \\
\hline
\end{tabular}

OR, odds ratio; AOR, adjusted odds ratio; $95 \%$ CI, 95\% confidence interval

*The AOR on the basis of risk factors such as age, gender, hypertension, diabetes mellitus, TC, TG, LDL-C, HDL-C and smoking.

data did not support the association between miR-21 gene rs1292037 T $>$ C polymorphism and ischemic stroke risk.

Rs2043556T/C polymorphism of miR-605 gene was related to certain human diseases [31, 32]. A recent report showed that $\mathrm{rs} 2043556 \mathrm{~T} / \mathrm{C}$ did not associated with the recurrence of ischemic stroke [43]. In present study we found that $\mathrm{rs} 2043556 \mathrm{~T} / \mathrm{C}$ also did not associated with the ischemic stroke risk. Serums miR-605 levels also showed no significant difference between patients and controls. Besides, rs2043556T/C polymorphism did not associated with serum miR-605 level. These findings suggested that miR-605 gene rs2043556T/C polymorphism may not play role in the progression of ischemic stroke.

Although our results are promising, it should be noted that our study have several limitations. First, all subjects may not give the same battery of diagnostic clinical and laboratory tests; therefore, potential selection bias could not be ruled out and might influence the interpretation of the results. Further independent validation studies are required to confirm the stability of the current findings. Second, relative small sample size was selected to detect the serum microRNAs levels; the results should be further validated in larger sample studies. Third, for the loss of stroke subtype information, we could not analyze the role of microRNA polymorphisms in different subtypes of ischemic stroke. Finally, more advanced statistical methods and validation experiments should be applied to subsequent studies to explore the exact regulatory mechanism of miRNA gene polymorphisms in ischemic stroke.

In summary, miR-126 gene rs4636297G $>A$ polymorphism was associated with decreased risk of 
Table 3: Stratified analysis of miR-126, miR-21, and miR-605 polymorphisms on ischemic stroke Risk

\begin{tabular}{|c|c|c|c|c|c|c|}
\hline \multirow[t]{2}{*}{ Variables } & \multicolumn{2}{|c|}{ miR-126 $(G A+A A)$ vs. $G G$} & \multicolumn{2}{|c|}{ miR-21(TC+CC) vs.TT } & \multicolumn{2}{|c|}{ miR-605 (TC+CC) vs.TT } \\
\hline & $\mathbf{A O R}^{*}$ & $\mathbf{P}^{*}$ & $\mathbf{A O R}^{*}$ & $\mathbf{P}^{*}$ & $\mathbf{A O R}^{*}$ & $\mathbf{P}^{*}$ \\
\hline \multicolumn{7}{|l|}{ Age } \\
\hline$<60$ & $1.43(0.81-1.70)$ & 0.210 & $0.87(0.55-1.39)$ & 0.560 & $1.04(0.67-1.61)$ & 0.858 \\
\hline$\geq 60$ & $1.14(0.78-1.94)$ & 0.180 & $1.40(0.98-1.98)$ & 0.063 & $1.23(0.88-1.72)$ & 0.218 \\
\hline \multicolumn{7}{|l|}{ Gender } \\
\hline Male & $1.37(0.84-1.82)$ & 0.210 & $1.33(0.93-1.91)$ & 0.117 & $1.14(0.81-1.61)$ & 0.446 \\
\hline Female & $1.10(0.61-1.58)$ & 0.249 & $1.02(0.65-1.59)$ & 0.945 & $1.23(0.81-1.87)$ & 0.326 \\
\hline \multicolumn{7}{|l|}{$\begin{array}{l}\text { Diabetes } \\
\text { mellitus }\end{array}$} \\
\hline Yes & $0.53(0.27-1.74)$ & 0.165 & $0.97(0.48-1.96)$ & 0.934 & $1.09(0.57-2.07)$ & 0.803 \\
\hline No & $1.22(0.76-1.84)$ & 0.178 & $1.23(0.91-1.68)$ & 0.181 & $1.71(0.88-1.56)$ & 0.284 \\
\hline \multicolumn{7}{|c|}{ Hypertension } \\
\hline Yes & $1.11(0.65-1.88)$ & 0.710 & $1.34(0.87-2.06)$ & 0.189 & $1.22(0.80-1.84)$ & 0.356 \\
\hline No & $1.22(0.73-1.90)$ & 0.211 & $1.17(0.86-1.59)$ & 0.327 & $0.85(0.58-1.25)$ & 0.406 \\
\hline \multicolumn{7}{|l|}{ Smoke } \\
\hline Yes & $1.57(0.93-2.66)$ & 0.193 & $1.51(0.92-2.47)$ & 0.102 & $1.10(0.68-1.77)$ & 0.697 \\
\hline No & $1.38(0.91-1.81)$ & 0.231 & $1.05(0.75-1.46)$ & 0.797 & $1.22(0.89-1.68)$ & 0.221 \\
\hline \multicolumn{7}{|c|}{ Hyperlipidemia } \\
\hline Yes & $0.85(0.54-1.34)$ & 0.476 & $0.84(0.54-1.32)$ & 0.454 & $0.82(0.52-1.28)$ & 0.380 \\
\hline No & $1.16(0.82-1.63)$ & 0.396 & $1.18(0.53-1.8)$ & 0.335 & $1.78(0.84-1.65)$ & 0.349 \\
\hline
\end{tabular}

AOR, adjusted odds ratio; 95\% CI, 95\% confidence interval

*The AOR on the basis of risk factors such as age, gender, hypertension, diabetes mellitus, hyperlipidemia and smoking.
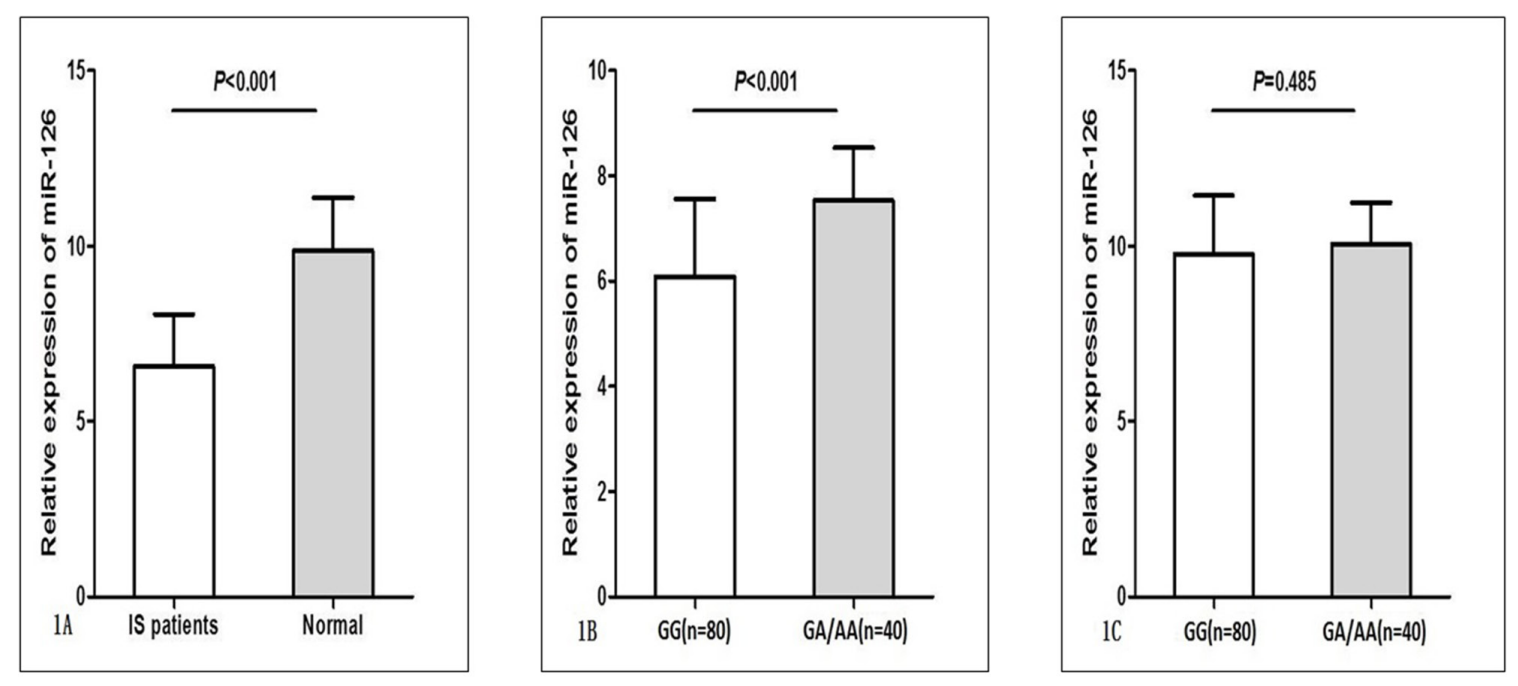

Figure 1: Relative expression of miR-126 (normalized to U6) in ischemic stroke (IS) patients (n $=120)$ and normal controls $(\mathbf{n}=\mathbf{1 2 0})$. (A) Serum levels of miR-126 were significantly decreased in IS patients compared with normal controls. (B) IS patients carrying rs4636297GA/AA genotypes had significant high serum levels of miR-126. (C) In normal controls rs4636297G $>A$ polymorphism did not associated with serum miR-126 level. Data were presented as mean \pm standard error. 
ischemic stroke. Significant changes in the circulating levels of miR-126 and miR-21 in ischemic stroke patients indicating that miR-126 and miR-21 might be potential diagnosis biomarkers or therapeutic targets for ischemic stroke.

\section{MATERIALS AND METHODS}

\section{Study subjects}

The study was performed with the approval of the ethics committee of the Affiliated Hospital of Youjiang Medical University for Nationalities, and written informed consent was obtained from all the subjects. The experiments were performed in accordance with relevant guidelines and regulations. The study included 592 ischemic stroke patients (367 males and 225 females) from the Department of Neurology, Affiliated Hospital of Youjiang Medical University for Nationalities, Guangxi, China between January 2013 and September 2015. The diagnosis of ischemic stroke was based on the appearance of a new and abrupt focal neurological deficit, with neurological symptoms and signs persisting for more than $24 \mathrm{~h}$. Ischemic stroke was confirmed by the positive findings by head CT or MRI according to the International Classification of Disease (9th Revision, codes 430 to 438). Patients with hemorrhagic stroke, coronary heart disease, autoimmune diseases, cancers or other serious diseases were excluded from the study. The 456 sexes- and age- matched controls (275 males and 181 females) were selected from volunteers who underwent physical examination in health examination center, Affiliated Hospital of Youjiang Medical University for Nationalities, Guangxi, China during the same period. Confirmed by head CT, MRI scanning (negative imaging finding) and thorough clinical and laboratory evaluation, the healthy volunteers meeting the same exclusion criteria as the cases were enrolled in this study.

Clinical information, such as hypertension, diabetes, fasting serum levels of total cholesterol (TCH), triglyceride (TG), high-density lipoprotein cholesterol (HDL-C), and lowdensity lipoprotein cholesterol (LDL-C) was abstracted from medical record review. All study subjects were Chinese and resided in the same geographic area in Guangxi China.

\section{SNPs selection}

We selected three common microRNA polymorphisms (miR-21T $>$ C [rs1292037], miR-126G $>$ A [rs4636297] and miR-605T $>\mathrm{C}$ [rs2043556]) which have been identified in a variety of human diseases [28-34].

\section{DNA extraction}

Genomic DNA was extracted from blood leucocytes by using a whole-blood genome DNA extraction reagent kit [Axygene Biotechnology (Hangzhou) Limited (Hangzhou City, China)], following the manufacturers' instructions.

\section{Determination of genotype}

The method of Snapshot SNP genotyping assay was taken to detect the allele and genotype frequencies. To confirm the genotyping results, PCR-amplified DNA samples were examined by DNA sequencing and the results were $100 \%$ concordant. The PCR primers were designed based on the GenBank reference sequence (accession no. miR-126: NC_000009.12; miR-21: NC_000017.11; miR-605: NC_000010.11).

\section{Quantitative PCR of microRNAs}

In all patients, plasma samples were collected within $12 \mathrm{~h}$ after symptom onset. After an overnight fasting, venous blood samples of control population were collected. Plasma was isolated by centrifugation and was maintained at $-70^{\circ} \mathrm{C}$ until use. 120 stroke patients and 120 normal controls were randomly selected to detecting serum microRNAs levels. Total RNA was isolated using a commercial kit (Qiagen, Hilden, Germany) following the manufacturer's protocol. One microgram of total RNA was reverse transcribed into cDNA utilizing reverse transcription kits from Ribobio Corp. (Guangzhou, China). After cDNA conversion, quantitative PCR was done using Power SYBR Master Mix and ABI 7500 real-time PCR machine (Applied Biosystems, CA, and USA). We purchased the primers from Ribobio Corp., (Guangzhou, China). U6 was used as an internal control. Relative expression levels of microRNAs were computed using comparative $\mathrm{Ct}$ method $\left(2^{-\Delta \mathrm{Ct}}\right)$.

\section{Statistical analysis}

The SPSS statistical software package version 17.0 was used for the statistical analysis. Continuous variables were displayed as mean $\pm \mathrm{SD}$. If the data were normally distributed, the Student's t-test was used; otherwise, Mann-Whitney U test was used. Categorical variables were expressed as proportions and compared by using chi-squared test. Hardy-Weinberg equilibrium (HWE) was tested by chi-squared test. The association of the miR$126 \mathrm{G}>\mathrm{A}$, miR-21T $>\mathrm{C}$ and $\mathrm{miR}-605 \mathrm{~T}>\mathrm{C}$ polymorphisms and risk of ischemic stroke was evaluated by odds ratios (ORs) with 95\% confidence interval (CIs). For multivariate analyses, logistic regression analyses were used to adjust for possible confounders, including age, sex, hypertension, diabetes mellitus, smoking, TCH, TG, HDL-C, and LDL-C. The power analysis was performed using NCSS-PASS 11.0. Statistical significance was accepted at the $\mathrm{P}<0.05$ level.

\section{Author contributions}

YX involved in study design, writing, revising the manuscript. JG, TT and HTH performed the experiment. HCL collected the data. YFP analyzed the data. YSW involved in study design and revising the manuscript. All authors read and approved the final manuscript. 


\section{CONFLICTS OF INTEREST}

The authors declare that they have no competing interest.

\section{FUNDING}

This study was supported by National Natural Science Foundation (No. 81260234, No. 81560552).

\section{REFERENCES}

1. Wang YL, Wu D, Liao X, Zhang W, Zhao X, Wang YJ. Burden of stroke in China. Int J Stroke. 2007; 2: 211-3. https://doi.org/10.1111/j.1747-4949.2007.00142.x.

2. Alperovitch A, Kurth T, Bertrand M, Ancelin ML, Helmer C, Debette S, Tzourio C. Primary prevention with lipid lowering drugs and long term risk of vascular events in older people: population based cohort study. BMJ. 2015; 350: h2335. https://doi.org/10.1136/bmj.h2335.

3. Lin MP, Ovbiagele B, Markovic D, Towfighi A. Association of Secondhand Smoke With Stroke Outcomes. Stroke. 2016; 47: 2828-35. https://doi.org/10.1161/strokeaha.116.014099.

4. Ning X, Sun J, Jiang R, Lu H, Bai L, Shi M, Tu J, Wu Y, Wang J, Zhang J. Increased Stroke Burdens Among the Low-Income Young and Middle Aged in Rural China. Stroke. 2016. https://doi.org/10.1161/strokeaha.116.014897.

5. Tadic M, Cuspidi C, Hering D. Hypertension and cognitive dysfunction in elderly: blood pressure management for this global burden. BMC Cardiovasc Disord. 2016; 16: 208. https://doi.org/10.1186/s12872-016-0386-0.

6. Wei YS, Xiang Y, Liao PH, Wang JL, Peng YF. An rs4705342 $\mathrm{T}>\mathrm{C}$ polymorphism in the promoter of miR$143 / 145$ is associated with a decreased risk of ischemic stroke. Sci Rep. 2016; 6: 34620. https://doi.org/10.1038/ srep34620.

7. Postula M, Janicki PK, Milanowski L, Pordzik J, Eyileten C, Karlinski M, Wylezol P, Solarska M, Czlonkowka A, Kurkowska-Jastrzebka I, Sugino S, Imamura Y, MirowskaGuzel D. Association of frequent genetic variants in platelet activation pathway genes with large-vessel ischemic stroke in Polish population. Platelets. 2016: 1-8. https://doi.org/10 $.1080 / 09537104.2016 .1203404$.

8. Pan Y, Chen W, Xu Y, Yi X, Han Y, Yang QW, Li X, Huang L, Johnston SC, Zhao X, Liu L, Zhang Q, Wang G, et al. Genetic Polymorphisms and Clopidogrel Efficacy for Acute Ischemic Stroke or Transient Ischemic Attack: A Systematic Review and Meta-analysis. Circulation. 2016. https://doi. org/10.1161/circulationaha.116.024913.

9. Asgeirsdottir SA, van Solingen C, Kurniati NF, Zwiers PJ, Heeringa $\mathrm{P}$, van Meurs M, Satchell SC, Saleem MA, Mathieson PW, Banas B, Kamps JA, Rabelink TJ, van Zonneveld AJ, et al. MicroRNA-126 contributes to renal microvascular heterogeneity of VCAM-1 protein expression in acute inflammation. Am J Physiol Renal Physiol. 2012; 302: F1630-9. https://doi.org/10.1152/ ajprenal.00400.2011.

10. Long G, Wang F, Li H, Yin Z, Sandip C, Lou Y, Wang Y, Chen C, Wang DW. Circulating miR-30a, miR126 and let-7b as biomarker for ischemic stroke in humans. BMC Neurol. 2013; 13: 178. https://doi. org/10.1186/1471-2377-13-178.

11. Volny O, Kasickova L, Coufalova D, Cimflova P, Novak J. microRNAs in Cerebrovascular Disease. Adv Exp Med Biol. 2015; 888: 155-95. https://doi. org/10.1007/978-3-319-22671-2_9.

12. Darabi F, Aghaei M, Movahedian A, Elahifar A, Pourmoghadas A, Sarrafzadegan N. Association of serum microRNA-21 levels with Visfatin, inflammation, and acute coronary syndromes. Heart Vessels. 2016. https://doi. org/10.1007/s00380-016-0913-Z.

13. Xiang ZL, Zhao XM, Zhang L, Yang P, Fan J, Tang ZY, Zeng ZC. MicroRNA-34a expression levels in serum and intratumoral tissue can predict bone metastasis in patients with hepatocellular carcinoma. Oncotarget. 2016; 7:8724687256. https://doi.org/10.18632/oncotarget.13531.

14. Ji R, Cheng Y, Yue J, Yang J, Liu X, Chen H, Dean DB, Zhang C. MicroRNA expression signature and antisensemediated depletion reveal an essential role of MicroRNA in vascular neointimal lesion formation. Circ Res. 2007; 100: 1579-88. https://doi.org/10.1161/circresaha.106.141986.

15. Hartmann D, Fiedler J, Sonnenschein K, Just A, Pfanne A, Zimmer K, Remke J, Foinquinos A, Butzlaff M, Schimmel K, Maegdefessel L, Hilfiker-Kleiner D, Lachmann N, et al. MicroRNA-based Therapy of Gata2-deficient Vascular Disease. Circulation. 2016. https://doi.org/10.1161/ circulationaha.116.022478.

16. Urbich C, Kuehbacher A, Dimmeler S. Role of microRNAs in vascular diseases, inflammation, and angiogenesis. Cardiovasc Res. 2008; 79: 581-8. https://doi.org/10.1093/ cvr/cvn156.

17. Schober A, Nazari-Jahantigh M, Wei Y, Bidzhekov K, Gremse F, Grommes J, Megens RT, Heyll K, Noels H, Hristov M, Wang S, Kiessling F, Olson EN, et al. MicroRNA-126-5p promotes endothelial proliferation and limits atherosclerosis by suppressing Dlk1. Nat Med. 2014; 20: 368-76. https://doi.org/10.1038/nm.3487.

18. Tsai PC, Liao YC, Wang YS, Lin HF, Lin RT, Juo SH. Serum microRNA-21 and microRNA-221 as potential biomarkers for cerebrovascular disease. J Vasc Res. 2013; 50: 346-54. https://doi.org/10.1159/000351767.

19. Kim JM, Jung KH, Chu K, Lee ST, Ban J, Moon J, Kim M, Lee SK, Roh JK. Atherosclerosis-Related Circulating MicroRNAs as a Predictor of Stroke Recurrence. Transl Stroke Res. 2015; 6: 191-7. https://doi.org/10.1007/ s12975-015-0390-1. 
20. Natarelli L, Schober A. MicroRNAs and the response to injury in atherosclerosis. Hamostaseologie. 2015; 35: 14250. https://doi.org/10.5482/hamo-14-10-0051.

21. Harnprasopwat R, Ha D, Toyoshima T, Lodish H, Tojo A, Kotani A. Alteration of processing induced by a single nucleotide polymorphism in pri-miR-126. Biochem Biophys Res Commun. 2010; 399: 117-22. https://doi. org/10.1016/j.bbrc.2010.07.009.

22. Ahn DH, Rah H, Choi YK, Jeon YJ, Min KT, Kwack K, Hong SP, Hwang SG, Kim NK. Association of the miR$146 \mathrm{aC}>\mathrm{G}, \quad \mathrm{miR}-149 \mathrm{~T}>\mathrm{C}, \quad \mathrm{miR}-196 \mathrm{a} 2 \mathrm{~T}>\mathrm{C}$, and $\mathrm{miR}-$ $499 \mathrm{~A}>\mathrm{G}$ polymorphisms with gastric cancer risk and survival in the Korean population. Mol Carcinog. 2013; 52: E39-51. https://doi.org/10.1002/mc.21962.

23. Kaudewitz D, Skroblin P, Bender LH, Barwari T, Willeit P, Pechlaner R, Sunderland NP, Willeit K, Morton AC, Armstrong PC, Chan MV, Lu R, Yin X, et al. Association of MicroRNAs and YRNAs With Platelet Function. Circ Res. 2016; 118: 420-32. https://doi.org/10.1161/ circresaha.114.305663.

24. Lee AR, Park J, Jung KJ, Jee SH, Kim-Yoon S. Genetic variation rs7930 in the miR-4273-5p target site is associated with a risk of colorectal cancer. Onco Targets Ther. 2016; 9: 6885-95. https://doi.org/10.2147/ott.s108787.

25. Jeon YJ, Kim OJ, Kim SY, Oh SH, Oh D, Kim OJ, Shin BS, Kim NK. Association of the miR-146a, miR-149, miR-196a2, and miR-499 polymorphisms with ischemic stroke and silent brain infarction risk. Arterioscler Thromb Vasc Biol. 2013; 33: 420-30. https://doi.org/10.1161/ atvbaha.112.300251.

26. Yuan M, Zhan Q, Duan X, Song B, Zeng S, Chen X, Yang Q, Xia J. A functional polymorphism at miR-491-5p binding site in the 3'-UTR of MMP-9 gene confers increased risk for atherosclerotic cerebral infarction in a Chinese population. Atherosclerosis. 2013; 226: 447-52. https://doi. org/10.1016/j.atherosclerosis.2012.11.026.

27. Qu JY, Xi J, Zhang YH, Zhang CN, Song L, Song Y, Hui RT, Chen JZ. Association of the MicroRNA-146a SNP rs2910164 with Ischemic Stroke Incidence and Prognosis in a Chinese Population. Int J Mol Sci. 2016; 17. https://doi. org/10.3390/ijms17050660.

28. Raelson JV, Little RD, Ruether A, Fournier H, Paquin B, Van Eerdewegh P, Bradley WE, Croteau P, Nguyen-Huu Q, Segal J, Debrus S, Allard R, Rosenstiel P, et al. Genomewide association study for Crohn's disease in the Quebec Founder Population identifies multiple validated disease loci. Proc Natl Acad Sci U S A. 2007; 104: 14747-52. https://doi.org/10.1073/pnas.0706645104.

29. Yang R, Dick M, Marme F, Schneeweiss A, Langheinz A, Hemminki K, Sutter C, Bugert P, Wappenschmidt B, Varon R, Schott S, Weber BH, Niederacher D, et al. Genetic variants within miR-126 and miR-335 are not associated with breast cancer risk. Breast Cancer Res Treat. 2011; 127: 549-54. https://doi.org/10.1007/ s10549-010-1244-x.
30. Yang J, Lan H, Huang X, Liu B, Tong Y. MicroRNA-126 inhibits tumor cell growth and its expression level correlates with poor survival in non-small cell lung cancer patients. PLoS One. 2012; 7: e42978. https://doi.org/10.1371/journal. pone. 0042978.

31. Hu Y, Yu CY, Wang JL, Guan J, Chen HY, Fang JY. MicroRNA sequence polymorphisms and the risk of different types of cancer. Sci Rep. 2014; 4: 3648. https:// doi.org/10.1038/srep03648.

32. Huang SP, Levesque E, Guillemette C, Yu CC, Huang CY, Lin VC, Chung IC, Chen LC, Laverdiere I, Lacombe L, Fradet Y, Chang TY, Lee HZ, et al. Genetic variants in microRNAs and microRNA target sites predict biochemical recurrence after radical prostatectomy in localized prostate cancer. Int J Cancer. 2014; 135: 2661-7. https://doi. org/10.1002/ijc.28904.

33. Chacon-Cortes D, Smith RA, Haupt LM, Lea RA, Youl $\mathrm{PH}$, Griffiths LR. Genetic association analysis of miRNA SNPs implicates MIR145 in breast cancer susceptibility. BMC Med Genet. 2015; 16: 107. https://doi.org/10.1186/ s12881-015-0248-0.

34. McAuley AK, Dirani M, Wang JJ, Connell PP, Lamoureux EL, Hewitt AW. A genetic variant regulating miR-126 is associated with sight threatening diabetic retinopathy. Diab Vasc Dis Res. 2015; 12: 133-8. https://doi. org/10.1177/1479164114560160.

35. Bonauer A, Boon RA, Dimmeler S. Vascular microRNAs. Curr Drug Targets. 2010; 11: 943-9.

36. Wang H, Peng W, Shen X, Huang Y, Ouyang X, Dai Y. Circulating levels of inflammation-associated miR-155 and endothelial-enriched miR-126 in patients with end-stage renal disease. Braz J Med Biol Res. 2012; 45: 1308-14.

37. Taibi F, Metzinger-Le Meuth V, M'Baya-Moutoula E, Djelouat M, Louvet L, Bugnicourt JM, Poirot S, Bengrine A, Chillon JM, Massy ZA, Metzinger L. Possible involvement of microRNAs in vascular damage in experimental chronic kidney disease. Biochim Biophys Acta. 2014; 1842: 88-98. https://doi.org/10.1016/j.bbadis.2013.10.005.

38. Raitoharju E, Oksala N, Lehtimaki T. MicroRNAs in the atherosclerotic plaque. Clin Chem. 2013; 59: 1708-21. https://doi.org/10.1373/clinchem.2013.204917.

39. Hartmann P, Schober A, Weber C. Chemokines and microRNAs in atherosclerosis. Cell Mol Life Sci. 2015; 72: 3253-66. https://doi.org/10.1007/s00018-015-1925-z.

40. Rink C, Khanna S. MicroRNA in ischemic stroke etiology and pathology. Physiol Genomics. 2011; 43: 521-8. https:// doi.org/10.1152/physiolgenomics.00158.2010.

41. Poliseno L, Tuccoli A, Mariani L, Evangelista M, Citti L, Woods K, Mercatanti A, Hammond S, Rainaldi G. MicroRNAs modulate the angiogenic properties of HUVECs. Blood. 2006; 108: 3068-71. https://doi. org/10.1182/blood-2006-01-012369.

42. Zhang Z, Xu G, Cai B, Zhang H, Zhu W, Liu X. Genetic Variants in MicroRNAs Predict Recurrence of Ischemic 
Stroke. Mol Neurobiol. 2016. https://doi.org/10.1007/ s12035-016-9865-7.

43. Wang M, Li W, Chang GQ, Ye CS, Ou JS, Li XX, Liu Y, Cheang TY, Huang XL, Wang SM. MicroRNA-21 regulates vascular smooth muscle cell function via targeting tropomyosin 1 in arteriosclerosis obliterans of lower extremities. Arterioscler Thromb Vasc Biol. 2011; 31: 204453. https://doi.org/10.1161/atvbaha.111.229559. 